\title{
Improving management of asthma: closing the loop or progressing along the audit spiral?
}

\author{
Departments of \\ Medical Audit and \\ Respiratory Medicine, \\ Glasgow Royal \\ Infirmary \\ C E Bucknall, medical \\ officer \\ F Moran, consultant \\ physician \\ R D Stevenson, \\ consultant physician \\ Department of \\ Statistics, University \\ of Strathclyde, \\ Glasgow \\ C Robertson, lecturer \\ Correspondence and reprints \\ C E Bucknall, Medical \\ Audit, Medical Division, \\ Glasgow Royal Infirmary, \\ Glasgow G4 0SF \\ Accepted for publication \\ 12 December 1991.
}

\author{
C E Bucknall, C Robertson, F Moran, R D Stevenson
}

\begin{abstract}
Objective - To assess whether the management of asthma has improved from three consecutive surveys.

Design - Retrospective case note survey of acute asthma admissions in 1983 and 1989; case notes selected from 1985-6 survey of prospectively identified patients to include only patients with a final discharge code of asthma.
\end{abstract}

Setting - A large city teaching hospital.

Patients - 101 patients with acute asthma as the primary diagnosis in 1983; 85 in 1985-6; and 133 in 1989, 14 of whom were subsequently transferred elsewhere.

Main measures - Conformity with a checklist of important aspects of the process of asthma management including initial assessment, treatment, supervision, and discharge and review arrangements.

Results - All patient groups were similar in age, smoking habit, and stay in hospital and, as an objective guide to severity of asthma, had similar initial pulse rates. Major improvements occurred in management: by 1989, $119(90 \%)$ patients were treated with oral corticosteroids $(69(68 \%), 67(79 \%)$ in 1983 , 1985-6 respectively) and $109(82 \%)$ with oxygen (62(61\%), $51(60 \%)$ (both p < 0.001). 114(86\%) had regular recording of peak flow measurements $(53(52 \%), \quad 54(64 \%) ; \quad p<0.001)$, and $103 / 119(86 \%)$ were discharged taking oral corticosteroids $\quad(66(65 \%), \quad 63(74 \%)$; p < 0.01). Significantly fewer patients, however, had their regular inhaled corticosteroid treatment increased on discharge $(38 / 119(32 \%) \quad v \quad 53(52 \%)$, $39(46 \%) ; p<0.01)$, but more were receiving high dose inhaled treatment on admission.

Conclusions - The management of asthma improved significantly, and the normal practice of doctors has changed in an area of practice with longstanding problems.

\section{Introduction}

Asthma is a condition which has attracted much attention in recent years, probably owing to the epidemic of deaths from asthma in the late 1960s in Britain. ${ }^{1}$ Several studies of deaths due to asthma showed deficiencies in care. ${ }^{2-7}$ More recently, the morbidity caused by asthma has been reported, ${ }^{8-10}$ and this has been associated with undertreatment. ${ }^{11-13}$

Our interest in the management of asthma began with a retrospective case note survey of management in this hospital in $1983 .{ }^{14}$ Subsequently, a prospective survey was carried out, ${ }^{10}$ which showed for the first time that in adults differences in managing acute asthma were associated with differences in outcome. ${ }^{13}$ These findings were widely discussed both within the hospital and more generally, and, subsequently, a further case note survey of asthma management was carried out, with identical methods to those used in the initial retrospective survey, to assess whether any change in practice had occurred.

\section{Patients and methods}

The case notes of all patients admitted to this hospital in 1983 and 1989 with a recorded diagnosis of asthma (ICD (ninth revision) codes 493.09, 493.19, 493.90, and 493.99) were examined. They were included in the survey if the admission was for acute asthma, either through the general practitioner or accident and emergency department or directly from an outpatient clinic.

In addition, the details of hospital management of some patients from the prospective audit in 1985-6 were extracted from the existing records. We included only patients with a discharge code of asthma in order to make this group comparable with those for 1983 and 1989, which were both identified retrospectively. In the 1985-6 audit we identified patients each day who were admitted with "asthma or wheezing illness in a non-smoker" but observed that in only 85 patients was acute asthma (83) or asthma with bronchitis (two) recorded on the discharge summary. We included this group of patients as they gave another reference point which helps to clarify the changes which were observed between 1983 and 1989.

Details of hospital management were recorded with a checklist, and demographic details such as age and sex, length of hospital stay, and history of smoking were recorded to allow description of the three groups. Regular treatment before admission was recorded with the intention of identifying some measure of severity of pre-existing asthma. Other items detailed included: (a) initial assessment (pulse, peak flow rate, blood gas analysis, recording of cyanosis, respiratory rate, and pulsus paradoxus); (b) treatment given (nebulised bronchodilators, steroids, amino- 
Table 1 Details of patients in three study groups

\begin{tabular}{lrrr}
\hline & 1983 & $1985-6$ & 1989 \\
\hline No & 101 & 85 & 133 \\
Median age (years) & 48 & 40 & 40 \\
No(\%) men & 43 & 40 & 29 \\
No(\%) non-smokers & 52 & 55 & 47 \\
Median hospital stay (days) & 5 & 5 & 4 \\
Median period of poor asthma & 3 & 2 & 3 \\
control, when recorded (days) & & & \\
\hline
\end{tabular}

phylline, and oxygen); (c) supervision (peak flow charting, assessment of inhaler technique, and repeat blood gas analysis); and (d) discharge and review arrangements (drugs on discharge and outpatient review plans).

Previous discussion of results - The 1983 survey served primarily as a pilot study and was not discussed at that stage. The prospective 1985-6 survey, which we consider to be of central importance, showed a relation between treatment and outcome, and its findings were presented at the hospital's main weekly meeting in 1987 attended by doctors of all disciplines. The findings were also discussed at each of the four medical units' internal weekly meetings at about the same time, when there was active discussion about their implications. The findings were published in $1988,{ }^{10} 13$ when they were again widely discussed. Audit meetings were not being held in our hospital over this period. The knowledge gained from the survey was included informally in teaching respiratory medicine to medical students, but formal guidelines were not produced at any stage.

Data presentation and analysis - Grouped data from each survey are presented as means and standard deviations or medians, as appropriate. When the numbers refer to less than the whole group, specific denominators are given. For pulse rate and other details of initial assessment the first recorded value is given, usually that recorded in the accident and emergency department. For peak flow rate the average of recordable values was taken. To assess whether the management of asthma had improved over the period of study results were analysed by $\chi^{2}$ testing for discrete variables with Yates's correction for small numbers, when appropriate, and $t$ tests for numerical data.

\section{Results}

PATIENTS

In the 1983 survey 101 of 165 patients admitted for asthma according to ICD (ninth revision) codes were included. Only three patients were excluded because the notes were not traceable; the others were excluded because acute asthma was not the primary diagnosis. In the 1989 survey 133 of 233 admitted patients identified from ICD (ninth revision) coding were included; only seven were excluded because the notes could not be traced. Thus in total only 10 of 398 patients (3\%) were excluded because the case notes were unobtainable. In the $1985-6$ survey 85 patients with a final diagnosis of asthma given by the admitting firm ( $53 \%$ of the patients followed up in 1985-6) were included in the analysis.

Table 1 shows some demographic details of the three patient groups. There was no change in the length of hospital stay over the survey period, and, in addition, the median stated period of poor asthma control remained short.
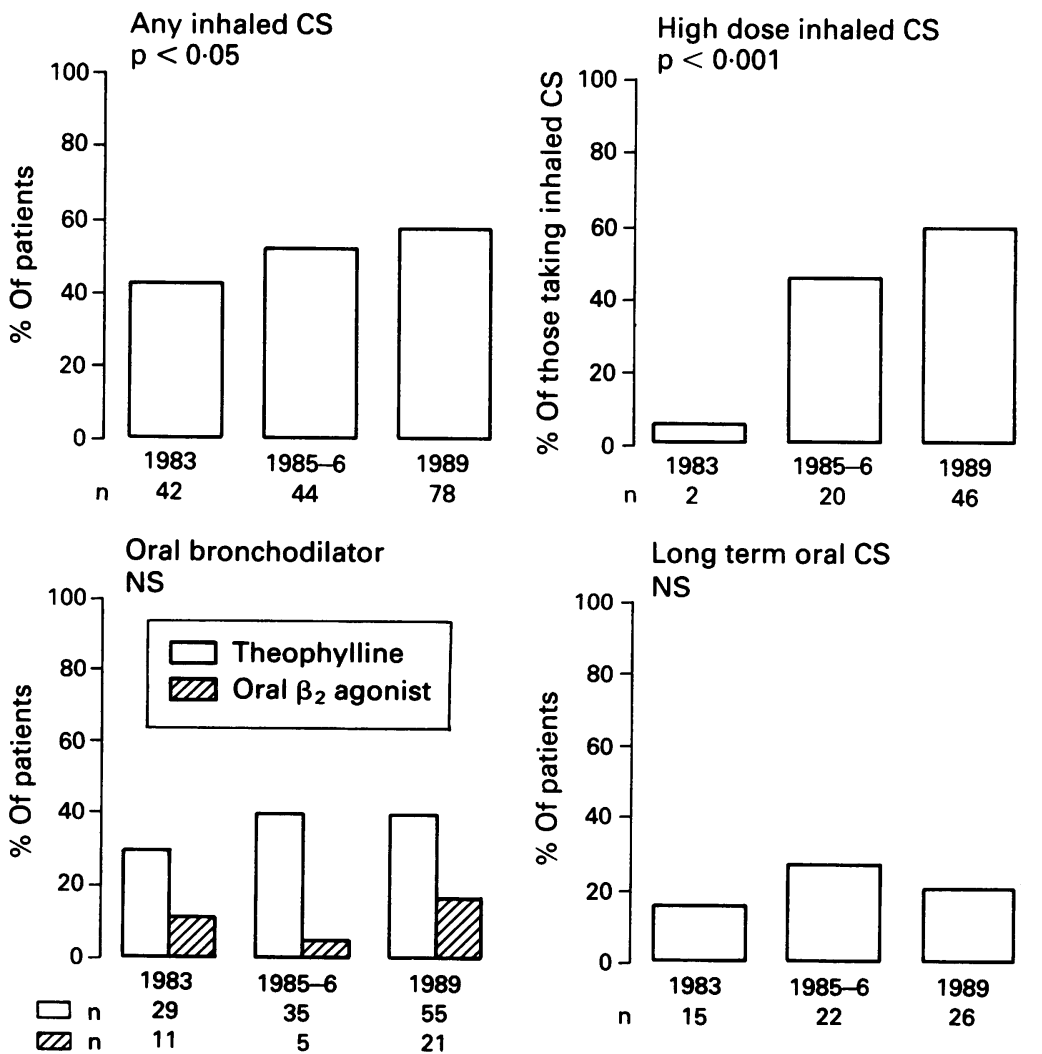

Fig 1 Regular drug treatment in patients with asthma before admission (CS corticosteroids) 
Table 2 Initial assessment of patients with asthma in hospital

\begin{tabular}{|c|c|c|c|}
\hline & 1983 & $1985-6$ & 1989 \\
\hline $\begin{array}{l}\text { Mean (SD) pulse rate on } \\
\text { admission (beats/min) }\end{array}$ & $111(18)$ & $112(20)$ & $111(21)$ \\
\hline No & 101 & 85 & 133 \\
\hline $\begin{array}{l}\text { Mean }(S D) \text { peak flow } \\
\text { rate }(1 / s)\end{array}$ & $163(144)^{\star}$ & $167(77)^{\star}$ & $147(63)$ \\
\hline No & 5 & 10 & 60 \\
\hline $\begin{array}{l}\text { No with unrecordable } \\
\text { peak flow rate }\end{array}$ & 3 & 3 & 6 \\
\hline
\end{tabular}

^Small denominators; as shown.

TREATMENT BEFORE INDEX ADMISSION

There was a significant increase in the proportion of patients who were receiving inhaled corticosteroids on admission from 42 patients $(42 \%)$ in 1983 to $78(59 \%)$ in 1989 $(\mathrm{p}<0.05)$ with a much larger difference in the use of high dose inhaled corticosteroids $(2,2 \%$ $v 46,35 \%$; $<<0.001$ ) (fig 1 ). The use of oral bronchodilators and long term oral corticosteroids over this period was unchanged.

INITIAL ASSESSMENT IN HOSPITAL

Severity of asthma - The average pulse and peak flow rates on admission were similar for the three periods (table 2). Three patients in 1983 and 1985-6 and six patients in 1989 had unrecordably low peak flow rates on admission. There was no difference in the proportion of patients who were severely hypoxaemic on admission $\left(\mathrm{pO}_{2}<8 \mathrm{kPa}\right.$ ) (fig $2)$. Inspired oxygen concentration was seldom quoted with blood gas tensions, but this applies to each survey period.

Assessment - There was a significant rise in the proportion of patients whose peak flow rates and arterial blood gas tensions were
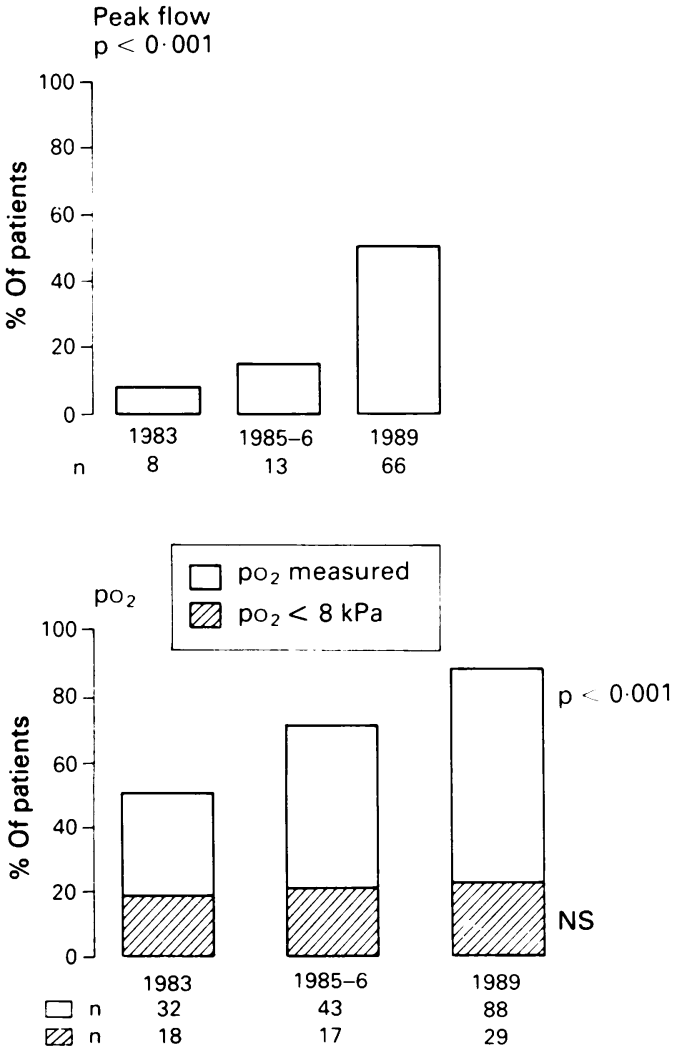

Fig 2 Initial assessment in hospital of patients with asthma measured as part of their initial assessment, to $66(50 \%)$ and $117(88 \%)$ respectively in 1989 (fig 2).

\section{HOSPITAL TREATMENT}

The proportion of patients treated with oral corticosteroids in hospital increased significantly from $69(68 \%)$ in 1983 , to $67(79 \%)$ in $1985-6$, and to $119(89 \%)$ in 1989 (fig 3). The median starting dose of prednisolone remained unchanged at $40 \mathrm{mg}$. The use of oxygen treatment also increased significantly with more patients being given high concentration oxygen $(>35 \%)$. Use of aminophylline declined overall.

\section{SUPERVISION IN HOSPITAL}

The recording of peak flow rates serially in hospital improved significantly from $53(52 \%)$ patients in 1983 , to $54(64 \%)$ in $1985-6$, and to $114(86 \%)$ in $1989(\mathrm{p}<0.001)$. There was no change in the recording of inhaler technique $(21(21 \%)$ patients, $16(19 \%)$, and $23(19 \%)$ for the three time periods). (The 1989 denominator was 119,14 patients being
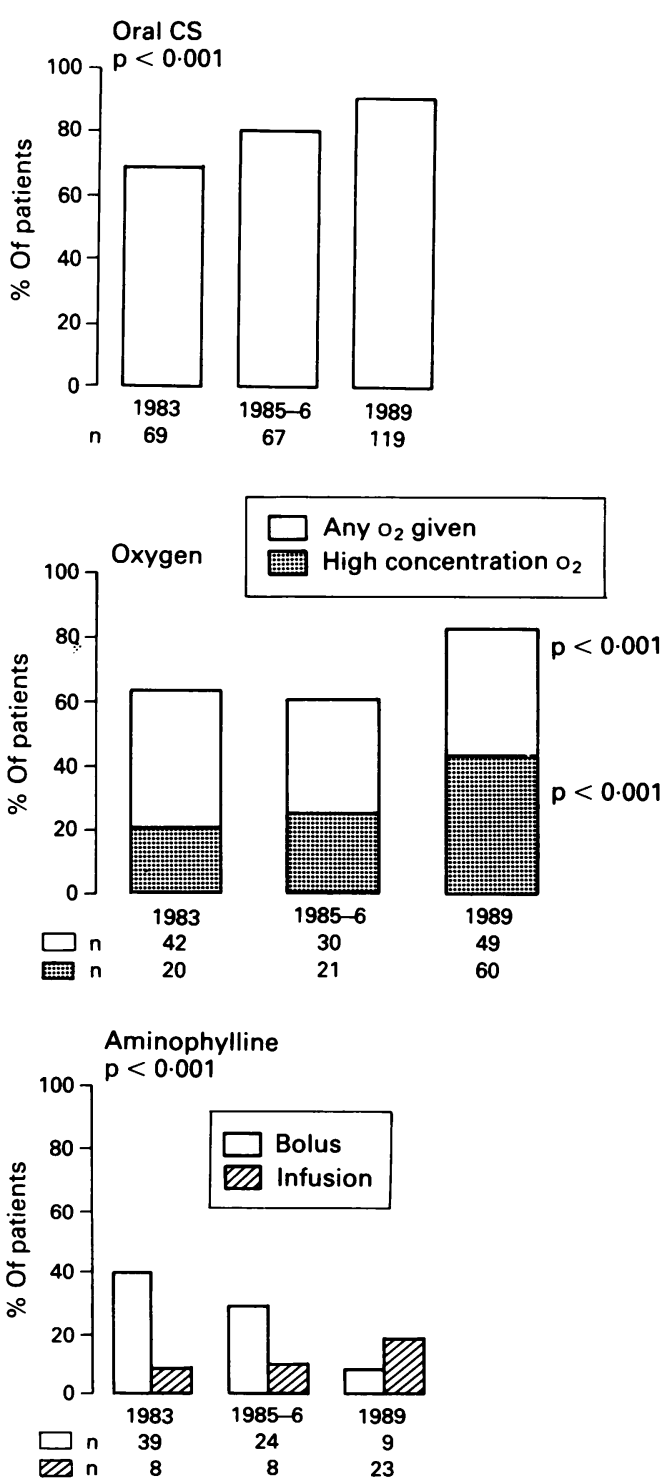

Fig 3 Treatment in hospital of patients with asthma (CS corticosteroids) 


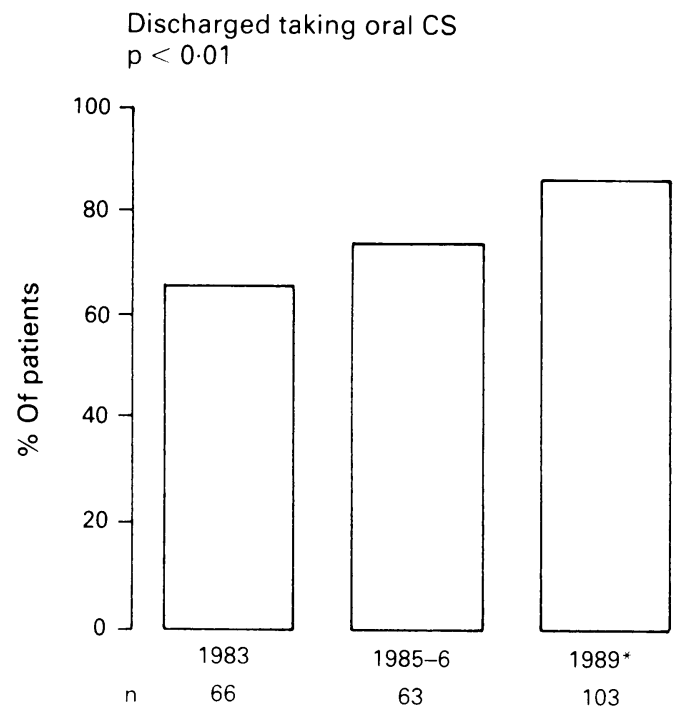

Inhaled CS increased on discharge $p<0.01$
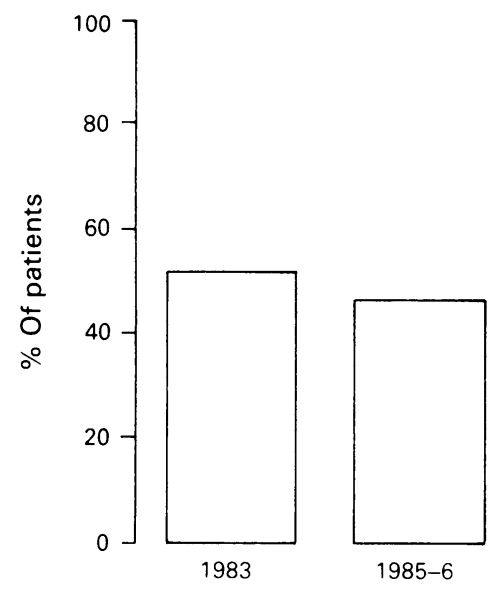

39

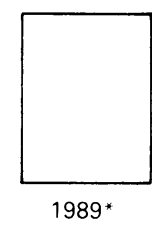

* Out of 119 patients

Fig 4 Steroid treatment after discharge (CS corticosteroids)

transferred after initial care to an adjacent specialised chest unit, from which they were subsequently discharged.) The proportion of patients who had blood gas analysis repeated was unchanged $(28(28 \%)$ in 1983 and $46(35 \%)$ in 1989$)$.

TREATMEN'T AFTER DISCHARGE AND

SUBSEQUENT SUPERVISION

Associated with the trend of increasing use of steroids in hospital, there was a significant increase in the proportion of patients discharged taking oral corticosteroids, $(\mathrm{p}<0.01)$ (fig 4). The median dose of

Table 3 Steroid treatment of patients with asthma after discharge

\begin{tabular}{|c|c|c|c|}
\hline & 1983 & $1985-6$ & 1989 \\
\hline No & 101 & 85 & $119^{\star}$ \\
\hline $\begin{array}{l}\text { No }(\%) \text { of patients where } \\
\text { reduction of prednisolone to } \\
\text { zero stated }\end{array}$ & $31(31)$ & $30(35)$ & $57(48)$ \\
\hline $\begin{array}{l}\text { Median time taking } \\
\text { prednịsolone (days) }\end{array}$ & 10 & 7.5 & 9 \\
\hline
\end{tabular}

* 14 patients transferred to adjacent chest unit for further treatment before discharge.
Table 4 Review arrangements for patients with asthma

\begin{tabular}{lccc}
\hline & 1983 & $1985-6$ & 1989 \\
\hline $\begin{array}{l}\text { No (\%) patients with review } \\
\text { planned }\end{array}$ & $76(75)$ & $64(75)$ & $95(79)^{\star}$ \\
$\begin{array}{l}\text { Ratio of respiratory to medical } \\
\text { clinic review appointments }\end{array}$ & $3.9: 1$ & $5.1: 1$ & $6.1: 1$ \\
$\begin{array}{l}\text { Median stated time to review } \\
\text { (weeks) }\end{array}$ & 4 & 2 & 3
\end{tabular}

*Out of 119 patients.

prednisolone on discharge was unchanged at $20 \mathrm{mg}$ in all groups. There was a significant decline in the proportion of patients whose long term inhaled corticosteroid treatment was increased at the time of discharge in 1989. The duration of taking oral corticosteroids after discharge in those instructed to reduce the dose to zero was unchanged (table 3 ).

There was no change in the proportion of patients being reviewed as outpatients or the time to this review recommended in the case notes. The proportion of patients for whom respiratory review was planned increased (table 4).

\section{Discussion}

The evidence presented here shows conclusively that the managenent of asthma in our hospital has improved. As we previously showed that differences in management were related to outcome, both in the short and medium term, it is reasonable to suggest that this improvement in process is probably associated with an improvement in outcome. A further prospective audit is under way to examine this.

Many aspects of the findings require further comment. The decline in numbers of patients from the stage of ICD coding to those entered into the study (234 out of $398,59 \%$ ) reflects the problems of coding acute asthma using ICD (ninth revision), there being only $3 \%$ of case notes unobtainable. ICD (ninth revision) allows for a code of status asthmaticus but does not differentiate less severe exacerbations of asthma from, for example, extrinsic or bronchial asthma. This is one aspect of coding which must be addressed by the Read coding initiative. Another concern is the issue of imprecise diagnostic coding by doctors. As described, only $53 \%$ of patients initially enrolled in the prospective survey in 1985-6 had a final diagnosis of asthma. Most of the rest were labelled as having chronic obstructive airway disease. Differences between these two groups have been described, ${ }^{15}$ but a central finding was that $68 \%$ either had previously proved reversible airways obstruction or gave a definite history of intermittent wheeze. Nevertheless, we included only this subgroup of the 1985-6 patients in order to make the three groups more comparable.

The three patient groups were sufficiently similar to allow valid comparison of details of management. They had a similar age and sex distribution, their stay in hospital was similar, and they had similar initial pulse and peak flow rates. We recorded regular drug treatment before admission to help to assess previous severity of asthma. By 1989 most patients taking inhaled corticosteroids (46/78, 59\%) 
were receiving a high dose $(>800 \mu \mathrm{g}$ of beclomethasone or equivalent). This is, however, probably related to the ready availability of this form of treatment by 1989 compared with at the beginning of the decade, perhaps with a better recognition that such patients were in an unstable phase of their condition. The hospital recording of duration of poor asthma control on admission continues to be underestimated; a much longer period of poor asthma control has been shown usually to precede the final event that leads to admission. ${ }^{13} 16$

Although initial assessment in hospital had improved, with $50 \%$ of patients having peak flow recorded and $88 \%$ their arterial blood gas tensions measured before treatment in 1989, further improvement is possible. In a recent audit from Central Middlesex Hospital Bell showed that $97 \%$ of patients with asthma had their peak flow recorded and $66 \%$ their arterial blood gas tensions measured. The reversal of these proportions in our hospital with a greater emphasis on peak flow recording might be facilitated if, as there, nursing staff always carried out this procedure. ${ }^{17}$

Recording of inhaler technique has remained static at about a fifth of all patients, compared with a sixth elsewhere. ${ }^{17}$ Data from the 1985-6 survey, in which patients were also questioned about their care, showed that for the whole survey group of 157 patients $61 \%$ recalled on direct questioning having had their inhaler technique checked whereas in only $18 \%$ of case notes was there evidence of this. This emphasises that important details of patient care are not always recorded in the case notes.

The central finding is that oral corticosteroids and oxygen are now being given in most patients and that the response to treatment is being monitored by the use of regular peak flow recording.

Inhaled treatment was increased at the time of discharge less often in 1989 than in earlier years. Many more patients already taking high dose inhaled corticosteroids, however, were admitted, perhaps leaving little room for further manoeuvre. (We could not assess retrospectively whether patients were actually complying with their stated treatment.) There was no change in the proportions of those not receiving inhaled corticosteroids, receiving low dose inhaled corticosteroids, and receiving high dose inhaled corticosteroids who had their inhaled treatment increased (data not shown), although the proportions of those having inhaled corticosteroid treatment started or increased was much higher (average $61 \%$ over the three surveys) for those not previously receiving inhaled corticosteroids than for those already receiving high dose corticosteroids (average $9 \%$ ). In addition, this change was not due to greater short term reliance on oral steroid treatment in 1989. The observed decline in the proportion of patients whose inhaled corticosteroid treatment was increased seems to reflect a different but related observation of the proportions of patients receiving different doses of inhaled steroids on admission. This analysis emphasises the importance of assessing results in context and in sufficient detail to be able to draw meaningful conclusions from the data.

Finally, it is interesting to speculate whether this local process of observing practice has brought about these changes or whether the widespread increased interest in asthma management has been more important. These studies were carried out before the British Thoracic Society guidelines ${ }^{18}$ and national asthma audit were under way. Nevertheless, if deaths from asthma were the preoccupation of the 1970 s morbidity associated with asthma has been an important underlying theme of much research in the $1980 \mathrm{~s}$. Analysis of trends in the data shows an equal proportion of important variables which changed progressively since 1983 (initial $\mathrm{pO}_{2}$ measured, peak flow charting, and use of oral steroids) as those which changed mainly after the 1985-6 survey (initial peak flow measured, oxygen treatment). Inhaled corticosteroid treatment after discharge showed a negative trend after 1985-6.

Such an analysis therefore shows some particular benefit from local audit activity in a field in which change was already occurring. Perhaps the best conclusion is that our surveys and discussion were pushing at an open door, providing a further impetus for change. This analysis is useful if one considers that the audit process works best when, as is commonly believed, a problem area is addressed. Whether or not a more active audit process, with greater clinician input is more beneficial is not known, although it seems likely.

Progress through the audit cycle has been made with a positive benefit. This is important as audit, if it is to develop, must be shown to be useful. However, the cycle is not complete and indeed may never be, with new problems constantly being highlighted by the latest survey. The audit spiral is here.

We thank Mrs J Morrison and staff of the medical records department, Glasgow Royal Infirmary, for unfailing help with case notes, and Mrs M Carruthers for preparing the manuscript. CEB was supported by the area medical audit committee.

1 Inman WHW, Adelstein AM. Rise and fall of asthma mortality in England and Wales in relation to use of pressurised aerosols. Lancet 1969;ii:279-85.

Cochrane GM, Clark TJH. A survey of asthma mortality in patients between ages 35 and 64 in the greater London hospitals in 1971. Thorax 1975;30:300-5.

MacDonald JB, MacDonald ET, Seaton A, Williams DA. Asthma deaths in Cardiff 1963-74: 53 deaths in hospital. $B M F$ 1976;ii:721-3.

4 MacDonald JB, Seaton A, Williams DA. Asthma deaths in Cardiff 1963-74: 90 deaths outside hospital. BMF $1976 ; \mathrm{i}: 1493-5$

5 Omerod LP, Stableforth DE. Asthma mortality in Birmingham 1975-7: 53 deaths. $B M F$ 1980;280: 687-90.

6 British Thoracic Association. Death from asthma in two regions of England. BMF 1982:285:1251-5.

7 Eason J, Markowe HLJ. Controlled investigation of deaths from asthma in hospitals in the North East Thames
fom from asthma in hospitals in

8 Horn CR, Cochrane GM. An audit of morbidity associated with chronic asthma in general practice. Resp Med with chronic

9 Crosbie FRG, Whyte E, Ogston S, Clark RA. Patterns of asthma in general practice. Thorax 1988;43:830P.

10 Bucknall CE, Robertson C, Moran F, Stevenson RD. Management of asthma in hospital: a prospective audit. $B M \mathcal{P}$ 1988: 296:1637-9. 
11 Horn CR, Cochrane GM. Management of asthma in general practice. Resp Med 1989;83:67-70.

12 Speight ANP, Lee DA, Hey EN. Underdiagnosis and undertreatment of asthma in childhood. $B M F$ 1983:286:1253-6.

13 Bucknall CE, Robertson C, Moran F, Stevenson RD. Differences in hospital asthma management. Lancet 1988;i:748-50.

14 Bucknall CE, Moran F, Stevenson RD. A retrospective survey of asthma management in hospital. Scot Med 7 survey of asthma
15 Bucknall CE, Robertson C, Moran F, Stevenson RD. Hospital management of asthmatic patients compared with those given a diagnostic label of "COAD". Thorax 1988;43:83OP.

16 Bellamy D, Collins JV. "Acute" asthma in adults. Thorax 1979;34:36-9.

17 Bell D, Layton AJ, Gabbay J. Use of a guideline based questionnaire to audit hospital care of acute asthma. BMF 1991;302:1440--3.

18 British Thoracic Society. Guidelines for management of asthma in adults. II. Acute severe asthma. BM7 1990; 301:797-800. 